\title{
A study of wrist injuries in children: the in- cidence of various injuries and of premature closure of the distal radial growth plate
}

\author{
D. I. FODDEN
}

St James's University Hospital, Beckett Street, Leeds

\section{SUMMARY}

There were 362 wrist injuries in 359 patients under 18 years of age who attended the Accident \& Emergency Department, St James's University Hospital, Leeds, over a 1-year period. These included soft tissue injuries (53\%), epiphyseal injuries $(4 \%)$ and fractures of the distal forearm or carpus $(43 \%)$ which were reviewed 3 years after injury. At re-examination, a repeat $\mathrm{X}$-ray was undertaken and this showed evidence of premature epiphyseal fusion in three of the 281 who returned for review and in these three patients there was a history of persistent symptoms in the affected wrist or forearm. It is suggested that patients with an obvious epiphyseal injury or those who have persistent symptoms following an injury to the wrist should be followed carefully to skeletal maturity in order to detect early partial or total closure of the growth plate.

\section{INTRODUCTION}

Patients with wrist injuries form a significant workload of an A\&E department. The majority have no bony injury either clinically or radiologically. Seven per cent of children presenting with a bony injury (Lee et al., 1984) or between $1.4 \%$ and $13 \%$ of patients presenting with an epiphyseal injury (Oh et al., 1974; Pappas, 1983; Mizuta et al., 1987) may develop premature partial or complete fusion of the distal radial epiphysis with late growth disturbance.

Epiphyseal and growth plate injuries account for up to $15 \%$ of paediatric skeletal trauma (Sakikada, 1964; Ogden, 1981; Tredwell et al., 1984) of which between $28 \%$ and 58\% involve the distal radius (Peterson \& Peterson,. 1972; Oh et al., 1974; Mbindyo, 1979; Ogden, 1981; Mizuta et al., 1987). Epiphyseal injuries have been

Correspondence: D. I. Fodden MB ChB FRCS, Senior Registrar in Accident E Emergency Medicine, Royal Hallamshire Hospital, Glossop Road, Sheffield S10 2JF. 
classified and reviewed by several authors (Poland, 1898; Salter \& Harris, 1963; Aitken, 1965; Ogden, 1981) but perhaps the most widely used classification currently is that of Salter \& Harris (1963).

Pure type $\mathrm{V}$ growth plate injuries tend to affect children just prior to epiphyseal fusion (Rogers, 1970) and are postulated to occur after a longitudinal compression force along the bone or other trauma (Langenskiold, 1981; Klassen \& Peterson, 1982 ) but this has been contested in favour of local ischaemic damage caused by immobilization of the limb after trauma (Peterson \& Burkhart, 1981). The injury is not apparent radiographically at the time of injury but it affects the proliferating cartilage cells which in turn disturbs the subsequent development of the metaphysis.

This study was undertaken to determine the relative frequencies of injuries occurring about the wrist in children, the risk of premature growth plate fusion and the identification of risk or warning factors.

\section{METHODS}

The patient attendance register was searched over a 1-year period and the records of those patients under 18 years of age who had sustained a wrist injury having been caused by hyperextension were retrieved. The approval of the local Ethical Committee was obtained and both the patients and their parents were contacted by letter and asked to return to the department for clinical review and repeat $X$-rays 3 years after the original injury.

The patients were asked pertinent questions relating to the injury, hand dominance and of any other symptoms which had arisen in the wrist or forearm since the injury. Any patient or parent who declined repeat $\mathrm{X}$-ray and examination was interviewed by telephone.

The ranges of movement of both the injured and non-injured wrist and forearm were measured with a goniometer to the nearest $5^{\circ}$ and repeat $\mathrm{X}$-rays of both wrists were assessed independently by a Senior Registrar in Radiology and myself. Any abnormal X-rays were reported to the General Practitioner. The General Practitioners of any untraceable patients were contacted by telephone and questioned regarding symptoms which may have developed in the wrist or forearm.

\section{RESULTS}

There were 362 injuries in 359 patients out of a total of 18,876 patients under 18 years and a total of 72,602 new patients who attended during the 12 months of the study. This represents $1.92 \%$ of new young patients and $0.49 \%$ of all new patients. Fifty-four per cent were male and the age distribution is shown in Table 1. A total of 281 patients attended for review, leaving $22 \%$ who declined review.

Information was obtained by telephoning the family or the General Practitioner in a further 54 cases leaving $24(6.7 \%)$ for whom no follow-up data are available 
Table 1. Initial diagnoses and ages at diagnosis (fracture: \#).

\begin{tabular}{|c|c|c|c|c|c|c|c|c|c|c|c|c|}
\hline $\begin{array}{l}\text { Age } \\
\text { (Years) }\end{array}$ & \multicolumn{2}{|c|}{$\begin{array}{c}\text { Epiphyseal \# } \\
\text { M F }\end{array}$} & \multicolumn{2}{|c|}{$\begin{array}{l}\text { Scaphoid \# } \\
\text { M F }\end{array}$} & \multicolumn{2}{|c|}{ \# R/U } & \multicolumn{2}{|c|}{ GS \# R/U } & \multicolumn{2}{|c|}{ NBI } & \multicolumn{2}{|c|}{ Total } \\
\hline 1 & 0 & 0 & 0 & 0 & 0 & 0 & 0 & 0 & 0 & 0 & 0 & 0 \\
\hline 2 & 0 & 0 & 0 & 0 & 0 & 0 & 0 & 0 & 1 & 0 & 1 & 0 \\
\hline 3 & 0 & 0 & 0 & 0 & 0 & 0 & 1 & 0 & 0 & 0 & 1 & 0 \\
\hline 4 & 0 & 0 & 0 & 0 & 1 & 0 & 1 & 1 & 0 & 1 & 2 & 2 \\
\hline 5 & 0 & 0 & 0 & 0 & 2 & 0 & 1 & 2 & 0 & 0 & 3 & 2 \\
\hline 6 & 0 & 0 & 0 & 0 & 2 & 1 & 4 & 1 & 0 & 3 & 6 & 5 \\
\hline 7 & 0 & 0 & 0 & 0 & 6 & 2 & 1 & 4 & 0 & 1 & 7 & 7 \\
\hline 8 & 3 & 0 & 0 & 0 & 1 & 3 & 3 & 5 & 2 & 1 & 9 & 9 \\
\hline 9 & 0 & 0 & 0 & 0 & 1 & 3 & 8 & 6 & 4 & 5 & 13 & 14 \\
\hline 10 & 2 & 4 & 0 & 0 & 1 & 2 & 6 & 7 & 9 & 9 & 18 & 22 \\
\hline 11 & 0 & 0 & 0 & 0 & 1 & 5 & 6 & 6 & 12 & 18 & 18 & 29 \\
\hline 12 & 1 & 1 & 0 & 0 & 6 & 2 & 4 & 1 & 12 & 20 & 23 & 24 \\
\hline 13 & 2 & 0 & 0 & 1 & 8 & 2 & 8 & 3 & 17 & 17 & 35 & 23 \\
\hline 14 & 1 & 0 & 3 & 0 & 3 & 1 & 7 & 1 & 19 & 8 & 33 & 10 \\
\hline 15 & 0 & 0 & 1 & 0 & 7 & 0 & 1 & 1 & 18 & 15 & 27 & 16 \\
\hline 16 & 0 & 0 & 0 & 0 & 0 & 1 & 0 & 0 & 0 & 0 & 0 & 1 \\
\hline 17 & 0 & 0 & 0 & 0 & 0 & 0 & 0 & 0 & 0 & 1 & 0 & 1 \\
\hline Total & 9 & 5 & 4 & 1 & 39 & 22 & 51 & 38 & 94 & 99 & 197 & 165 \\
\hline Mean age & 10 & & 14 . & & 10 & & 9. & & 12 & .2 & 11. & \\
\hline S.D. age & $1 \cdot$ & 95 & 0. & 71 & & 15 & 2 . & 77 & & $\cdot 26$ & 2 & 73 \\
\hline
\end{tabular}

either directly or indirectly. The initial diagnoses are shown in Table 1 along with the mean and standard deviation of the age at the time of injury. There was little seasonal variation in the incidence of any particular injury. At initial X-ray there were 14 epiphyseal injuries, five scaphoid fractures, 61 complete and 89 greenstick fractures of the radius or ulna and a total of 193 with no apparent bony injury.

At follow up there were no significant differences in the ranges of joint movement in any group, one patient showed radiological evidence of premature fusion and a further two had developed a bone bar across the growth plate. The details of these three patients are shown in Table 2 and the remaining group which exhibited no evidence of premature closure of the growth plate had a mean age of 11.38 years with a standard deviation of 2.73 .

Table 2. Details of those patients who exhibited premature closure of the distal radial growth plate.

\begin{tabular}{|c|c|c|c|c|c|}
\hline Age & Sex & Side & Dominance & $\begin{array}{l}\text { Total or partial } \\
\text { fusion }\end{array}$ & Diagnosis \\
\hline 10 & M & $\mathrm{R}$ & $\mathbf{R}$ & Partial & Type II Injury \\
\hline 13 & M & $\mathrm{L}$ & $\mathbf{R}$ & Total & \# Radius \& Ulna \\
\hline 14 & $\mathrm{~F}$ & $\mathrm{R}$ & $\mathrm{L}$ & Partial & $\begin{array}{l}\text { Greenstick \# } \\
\text { Radius \& Ulna }\end{array}$ \\
\hline
\end{tabular}


Symptoms were noted in 15 patients more than 4 months after the injury and these persisted until review in a total of seven including the three patients who developed premature fusion of the distal radial epiphysis. Long lasting symptoms included aching, crepitus and weakness but there was no complaint of loss of movement.

\section{DISCUSSION}

Growth plate injuries occur with increasing frequency with advancing age until fusion, the peak age being 12 for boys and 11 for girls (Mizuta et al., 1987). Boys outnumber girls by $2: 1$ because of their greater exposure to trauma and the later epiphyseal fusion (Peterson \& Peterson, 1972). The relative frequencies of the different types of epiphyseal injuries from published series' are shown in Table 3 (Rogers, 1970; Oh et al., 1974; Mbindyo, 1979; Lee et al., 1984; Mizuta et al., 1987).

Type V injuries may accompany any other fracture or dislocation not involving the growth plate (Connolly et al., 1985) but typically occur in the absence of any other obvious bony injury. Type $\mathrm{V}$ growth plate injuries cannot be diagnosed radiologically at the time of injury but a crush injury may occur coincidentally with any other fracture involving the growth plate and will result in bone bar formation. Late deformity following a growth plate injury may be minimized by early, accurate, non-forceful reduction (Oh et al., 1974; Lee et al., 1984).

The prevalence of premature fusion of the growth plate varies between $1.4 \%$ and 75\% (Sakikada, 1964; Oh et al., 1974; Pappas, 1983; Lee et al., 1984; Mizuta et al., 1987) although the period of surveillance after the predisposing injury varies widely in these series' as does the rate of open reduction and internal fixation. It seems likely that patients with these injuries should be followed to skeletal maturity since growth arrest may develop up to 10 years after an injury to the growth plate (Klassen \& Peterson, 1982).

Patients with premature fusion of the distal radial epiphysis had a clinical course which was more protracted than for soft tissue trauma or a straightforward fracture of the distal forearm or carpus. Symptoms which may signify developing problems at the growth plate have been listed elsewhere (Lee et al., 1984) all of which were exhibited by the three patients in this series with the exception of decreased range of movement.

Table 3. Frequencies (\%) of different epiphyseal injuries.

\begin{tabular}{lrrrrrr}
\hline & Rogers & Oh & Mbindyo & Lee & Mizuta & Average \\
\hline Type I & 6 & 26 & 25 & 12 & 8 & 16 \\
Type II & 75 & 55 & 59 & 74 & 73 & 68 \\
Type III & 8 & 10 & 5 & 7 & 6 & 7 \\
Type IV & 10 & 9 & 8 & 2 & 12 & 8 \\
Type V & 1 & 0 & 3 & 1 & 1 & 1 \\
\hline
\end{tabular}


Patients with a prolonged history of problems around the wrist or those with an obvious growth plate injury should be followed up regularly until skeletal maturity in order to detect premature fusion or bone bar formation across the growth plate. Radiological evidence of premature fusion may occur without loss of function as shown in this series and by others (Rogers, 1970) so this should be borne in mind if operative treatment is contemplated.

\section{ACKNOWLEDGEMENTS}

I am grateful to Dr I. D. Adams and the late Mr P. L. Milsom for their help and guidance in preparing this paper.

\section{REFERENCES}

Aitken A. P. (1965) Fractures of the epiphyses. Clinical Orthopaedics and Related Research 41, $19-23$.

Connolly J. F., Eastman T. \& Huurman W. W. (1985) Torus fracture of the distal radius producing growth arrest. Nebraska Medical Journal 70, 204-207.

Klassen R. A. \& Peterson H. A. (1982) Excision of physeal bars: the Mayo Clinic experience 1968-1978. Orthopaedic Transactions 6, 65.

Langenskiold A. (1981) Surgical treatment of partial closure of the growth plate. Journal of Pediatric Orthopedics 1, 3-11.

Lee B. S. Esterhai J. L. \& Das M. (1984) Fracture of the distal radial epiphysis. Characteristics and surgical treatment of premature, post-traumatic epiphyseal closure. Clinical Orthopaedics and Related Research 185, 90-96.

Mbindyo B. S. (1979) Considerations on cases of epiphyseal injury observed at Kenyatta National Hospital. East African Medical Journal 56, 431-435.

Mizuta T. Benson W. M., Foster B. K., Paterson D. C. \& Morris L. L. (1987) Statistical analysis of the incidence of physeal injuries. Journal of Pediatric Orthopedics 7, 518-523.

Ogden J. A. (1981) Injury to the growth mechanisms of the immature skeleton. Skeletal Radiology 6, 237-253.

Oh W. H., Craig C. \& Banks H. H. (1974) Epiphyseal injuries. Pediatric Clinics of North America 21, 407-422.

Pappas A. M. (1983) Epiphyseal injuries in sports. Physician and Sports Medicine 11, 140-148.

Peterson C. A., Peterson H. A. (1972) Analysis of the incidence of injuries to the epiphyseal growth plate. Journal of Traunia 12, 275-281.

Peterson H. A. \& Burkhart S. S. (1981) Compression injury of the epiphyseal growth plate: fact or fiction? Journal of Pediatric Orthopedics 1, 377-384.

Poland J. (1898) Traumatic separation of the epiphyses. Smith Elder, London.

Rogers L. F. (1970) The radiography of epiphyseal injuries Radiology 96, 289-299.

Sakikada K. (1964) Clinical observations on the epiphysial separation of long bones. Clinical Orthopaedics and Related Research 34, 119-141.

Salter R. B. \& Harris W. R. (1963) Injuries involving the epiphyseal plate. Journal of Bone Joint Surgery (Am) 45A, 587-622.

Tredwell S. J. (1984) Peteghem K. V. Clough M. Pattern of forearm fractures in children. Journal of Pediatric Orthopedics 4, 604-608. 